\title{
What Can We Learn from Online Wage Postings? Evidence from Glassdoor
}

Marios Karabarbounis and Santiago Pinto

$\mathrm{T}$ racking economic activity and interpreting economic phenomena are the most basic functions of economic research. However, obtaining an accurate description of the economy - in the form of economic data-is a challenging endeavor. Basic economic variables such as gross domestic product, consumption expenditures, investment, real wages, and others are available at the aggregate level. They are useful for time-series analysis but not to study issues such as wage or wealth inequality. To study heterogeneity, economists rely on household-level data from sources like the Panel Study of Income Dynamics (PSID), the Survey of Consumer Finances, or the Consumption Expenditure Survey. However, these typically include only a sample of the population and are often subject to measurement errors.

For this reason, economists have recently started to incorporate alternative sources that provide granular or disaggregated data, for example, websites that offer job and recruiting services. A growing number of sites give online information about different jobs around the US and worldwide. The websites collect, at the same time, personal and financial data from users. In light of this recent phenomenon, a question naturally arises: Can economists view these websites as a reliable source of new information? ${ }^{1}$

\footnotetext{
- Contact information: marios.karabarbounis@rich.frb.org and santiago.pinto@rich.frb.org. We thank Andrew Chamberlain and Glassdoor for generously providing us with the data. For useful comments, we thank Andreas Hornstein, John Bailey Jones, and John Weinberg. We also thank Mohamed Abbas Roshanali for outstanding research assistance. Any opinions expressed are those of the authors and do not necessarily reflect those of the Federal Reserve Bank of Richmond or the Federal Reserve System. DOI: https://doi.org/10.21144/eq1040402

${ }^{1}$ Kudlyak et al. (2013) employ information from an online posting website to analyze how job seekers direct their applications over the course of job search. Hershbein
} 
In this paper, we take a small step toward addressing this issue. We present information from millions of salaries from Glassdoor.com (henceforth, Glassdoor), a leading job website that helps people find jobs and companies recruit employees. To use the service, registered users are asked, among other things, to report their current occupation title (job position), company, salary (in addition to other payment schemes), location, and level of experience. In return, users can get access to user-generated content including ratings and reviews of companies, interview questions, CEO approval rates, and summary statistics of salaries for job positions within each company.

We compare the salary information in Glassdoor with two other widely used sources. The first is the Quarterly Census for Employment and Wages (QCEW) published by the US Census Bureau. QCEW provides information on salaries and employment at various industry and geographic area levels. The second is the PSID, which includes a long panel of data available at the household level. Both datasets are frequently used as sources of information by researchers. ${ }^{2}$

There are two main concerns with using data from an online posting site such as Glassdoor. First, online data may not be representative of the population. Our first - and not surprising - finding is that user entries in Glassdoor do not accurately represent the national employment distribution across industries. For example, Glassdoor is overrepresented in industries such as information technology, finance, and telecommunications. In contrast, it is underrepresented in industries such as construction, restaurants and food services, and especially health care. We find that the Glassdoor data, however, are wellrepresented across metropolitan statistical areas (MSAs), with a correlation of the share of user entries by MSA in Glassdoor and QCEW of 0.94. However, we consider the industry misrepresentation more important, as labor income is likely to depend more on industry rather than regional characteristics. Nevertheless, estimating a population mean on the basis of a sample that fails to represent the target population can be addressed by weighting the entries. ${ }^{3}$

The second, and more important, issue is potential measurement error. Online respondents may intentionally or unintentionally misreport their salary. We test for the presence of measurement error by

and Kahn (2017) use online job postings to show that skill requirements differentially increased in MSAs that were hit hard by the Great Recession.

${ }^{2}$ Chamberlain and Nunez (2016) develop a statistical model based on Glassdoor data and compare median weekly earnings of full-time wage and salary workers to the Current Population Survey, which covers about 60,000 households. The authors report a relatively small deviation between the two, around 5 percent.

${ }^{3}$ For more on this topic, the reader can refer to the paper by Solon et al. (2013). 
Karabarbounis \& Pinto: What Can We Learn from Online Wage Postings?175

comparing the mean and the standard deviation of the distribution of salaries in Glassdoor, conditional on a group characteristic, with the respective moments in QCEW and PSID. We focus on two characteristics, the worker's industry and region.

When we compare average salaries between Glassdoor and QCEW, we find a reasonably high correlation both across industries and regions. For example, in the real estate sector, the average salaries in QCEW and Glassdoor are $\$ 52,509$ and $\$ 51,805$, respectively; in entertainment, they are $\$ 36,118$ and $\$ 39,395$, respectively; and in manufacturing, they are $\$ 64,999$ and $\$ 63,964$, respectively. The most important discrepancies between Glassdoor and QCEW are observed in industries where workers receive high salaries. These include finance, media, and biotech and pharmaceutical. Overall, the crossindustry correlation between QCEW and Glassdoor is 0.87 . When we compute the correlation of average annual salaries across MSAs, we find a correlation of 0.83.

PSID gives an even higher correlation in average wages when it is compared to Glassdoor (equal to 0.9). When we compare the within industry dispersion between salaries in Glassdoor and PSID, we find a correlation of 0.77 , which is still high but considerably lower than the correlation in average salaries.

We conclude that the wage distribution (conditional on industry or region) in Glassdoor represents the respective distributions in other datasets, such as QCEW and PSID fairly well. In contrast, the industry employment shares in Glassdoor do not represent the employment distribution across industries in the US well.

\section{DESCRIPTION OF DATASETS}

\section{Data from Glassdoor}

Glassdoor is one of the leading job sites people use to find jobs and companies use to recruit prospective employees. Users are required to register in order to access user-generated content, which includes company ratings and reviews, typical job interview questions, and $\mathrm{CEO}$ approval rates, among other things. Glassdoor requires all registered users to provide some information about their current job, such as their occupation title (job position), the name of the company, and their salary. Users describe their sources of income as well: they distinguish between annual salary (or hourly wage rate) and tips, stock options, or bonuses. They also post information about their experience and the geographical location of the job, described by the city name.

We examine around 6 million salary entries in the Glassdoor database. Figure 1 plots the total number of salary entries by year (flow). As the website became more popular, the number of online users has 
Figure 1 User Entries in Glassdoor

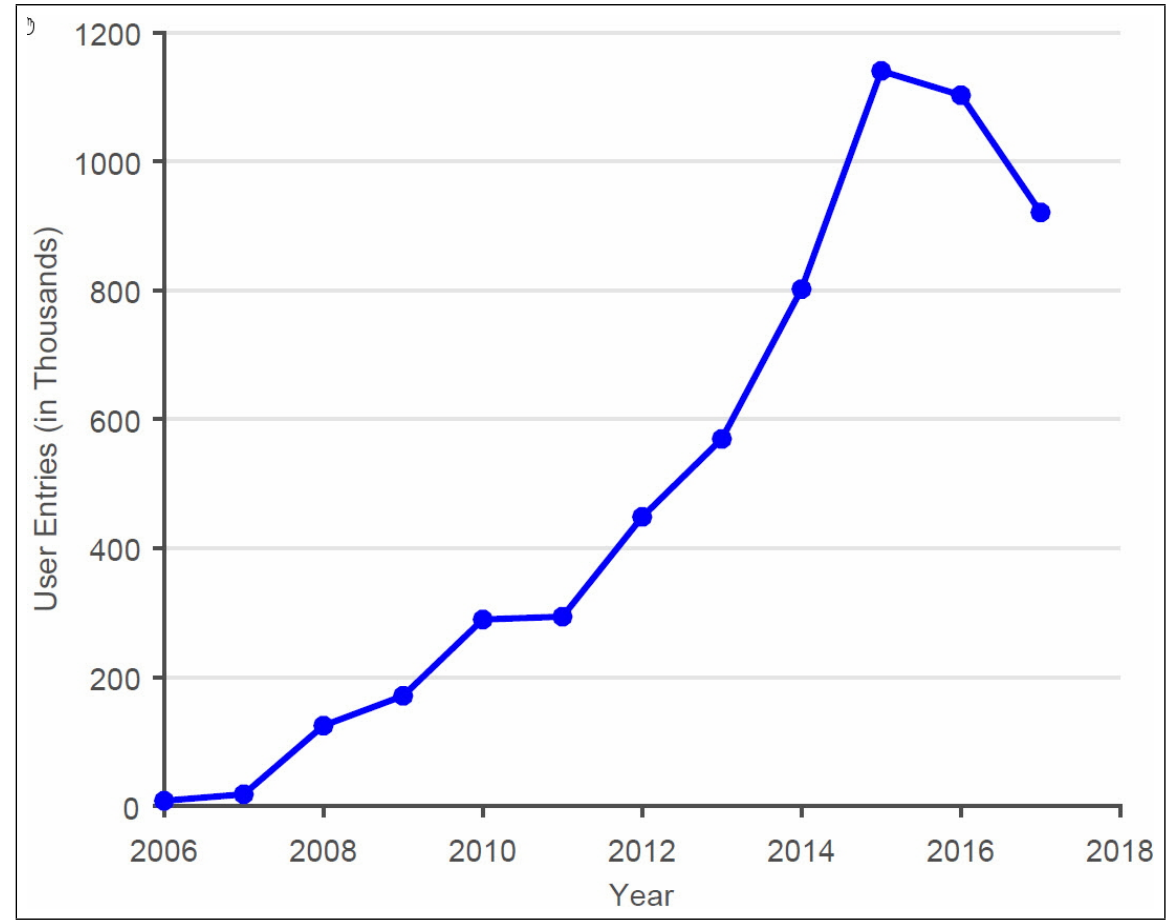

Notes: Number of new user entries in website between 2006-17. Entries are reported in thousands.

been expanding. Between 2010 and 2017, the user entries went from around 290,000 to around 1,100,000. We also have 218,462 observations for the first five months of 2018, which we include in the analysis.

Each user has a unique ID number. Since a user may have reported multiple salaries for the same or different jobs, there may be multiple salary entries per user. However, very few users do so. Specifically, 96.4 percent of the users reported one salary, 3.1 percent two salaries, and 0.4 percent three salaries. For each entry we have the exact date of the record, the user's job title, salary, company name, industry, and city name.

Job titles can range from graphic designer, bartender, and nanny to sales associate, project manager, and engineer. There are 190,336 distinct job titles in Glassdoor. Table 1 shows the twenty most common job titles found in the data and their respective shares as a fraction of 
Karabarbounis \& Pinto: What Can We Learn from Online Wage Postings?177

Table 1 Most Common Job Titles and Companies in Glassdoor

\begin{tabular}{llll}
\hline \multicolumn{1}{c}{ Job titles } & & \multicolumn{2}{c}{ Companies } \\
\hline Job title & Freq. & Company & Freq. \\
\hline Manager & $4.86 \%$ & Amazon.com & $1.29 \%$ \\
Software engineer & $2.79 \%$ & Deloitte & $0.78 \%$ \\
Sales associate & $2.29 \%$ & AT\&T & $0.76 \%$ \\
Project manager & $1.73 \%$ & Target & $0.68 \%$ \\
Store manager & $1.68 \%$ & Walmart & $0.64 \%$ \\
Cashier & $1.46 \%$ & Ernst and Young & $0.52 \%$ \\
Customer serv. representative & $1.42 \%$ & Wells Fargo & $0.46 \%$ \\
Account manager & $1.27 \%$ & Microsoft & $0.45 \%$ \\
Consultant & $1.19 \%$ & Bank of America & $0.45 \%$ \\
Intern & $1.09 \%$ & IBM & $0.41 \%$ \\
Account executive & $1.08 \%$ & Best Buy & $0.40 \%$ \\
Engineer & $1.01 \%$ & Home Depot & $0.37 \%$ \\
Operations manager & $0.96 \%$ & Starbucks & $0.37 \%$ \\
Administrative assistant & $0.94 \%$ & Lowe's & $0.35 \%$ \\
Registered nurse & $0.88 \%$ & J.P. Morgan & $0.34 \%$ \\
Associate & $0.88 \%$ & Apple & $0.32 \%$ \\
Analyst & $0.87 \%$ & Walgreens & $0.32 \%$ \\
Marketing manager & $0.84 \%$ & PwC & $0.31 \%$ \\
Business analyst & $0.82 \%$ & Macy's & $0.31 \%$ \\
Sales representative & $0.82 \%$ & US Army & $0.31 \%$ \\
\hline
\end{tabular}

Notes: The twenty most common job positions and companies as they appear in Glassdoor. Frequency is the number of user entries in Glassdoor in a specific job position/company as a fraction of total user entries across all years.

the total number of observations. The job with the highest representation is manager followed by software engineer. This makes sense as workers in these job positions are more likely to feel comfortable using job-posting websites. In addition, there are many jobs affiliated with the retail sector, such as retail sales associate, store manager, cashier, and sales representative. Other frequent jobs include analyst, different types of accountants, and project managers.

We perform a similar analysis with respect to companies. There are 222,982 distinct companies in Glassdoor. Companies with the highest representation are most often in the retail sector: Target, Walmart, Amazon.com, Best Buy, Macy's, and others. The others are in software and electronic product development such as Microsoft, IBM, and Apple, or in the financial sector such as Wells Fargo, Bank of America, JPMorgan, and PricewaterhouseCoopers. Although not reported in the table, we also find the cities with the highest representation. There are 17,437 distinct cities. The most-represented city is New York (6.5 
percent), followed by Chicago (3.2 percent), San Francisco (2.3 percent), Houston (2.1 percent), Atlanta (2.1 percent), Los Angeles (2.0 percent), Seattle (1.9 percent), Washington (1.8 percent), Boston (1.8 percent), Dallas (1.7 percent), and Austin (1.3 percent).

Users can report their labor income payments at an annual or hourly frequency. When users are asked about their salary, they are asked about their base pay as well as cash bonuses, stock bonuses, profit shares, commissions, and tips. Around 64 percent of observations have annual salary entries, while 34 percent have hourly rates. Around 2 percent report their labor earnings in a monthly frequency. About 23 percent of our sample has information on cash bonuses, 3 percent on stock bonuses, 3 percent on profit sharing, 6 percent on commissions, and 1 percent on tips.

Users also report years of experience. This variable (available for 99.9 percent of the entries) takes values between zero and sixty. In the database, 16 percent report zero years of experience, 9 percent report five years, 6 percent report ten years, 3 percent report fifteen years, and 3 percent report twenty years. Glassdoor also provides some demographic characteristics about the users. Available information includes the users' highest education level, gender, and race. From all Glassdoor responses, 34 percent have nonmissing entries for highest attained education level, 66 percent for gender, and 5 percent for race.

\section{Quarterly Census of Employment and Wages}

The Department of Labor's Bureau of Labor Statistics (BLS) runs and maintains three datasets that examine and track the behavior of labor markets at the state and local levels: the Current Employment Statistics, the Local Area Unemployment Statistics, and the QCEW. From all these sources, the most reliable and straightforward counterpart to the Glassdoor data are the data released by the QCEW program.

QCEW provides thorough information on the number of establishments, monthly employment, and quarterly wages in the US. The data are collected from state and federal unemployment insurance records. Since approximately 9 million businesses report this information to state and federal unemployment insurance agencies, the data cover 98 percent of all salary and civilian employment in the country. The information is available at different levels of geographical detail (MSA, county, state, and national levels) and industry detail (down to six-digit NAICS codes). We use data from the period 2010-16, which roughly correspond to the years of data available on Glassdoor.

QCEW data have some limitations, which we briefly describe here. First, for confidentiality reasons, nearly 60 percent of the most detailed 
Karabarbounis \& Pinto: What Can We Learn from Online Wage Postings?179

level data are suppressed. Second, QCEW does not account for some categories of employment such as self-employed, nonprofit, and military workers, among others. And third, the way the data are collected by states may not be fully consistent, since standards for unemployment insurance coverage vary across states.

\section{Panel Study of Income Dynamics}

The PSID includes a long panel of households. The survey was conducted annually until 1997 and biannually from 1999-2015. We use, in the present analysis, data from the period 2003-11. For each year, we use the information associated with the head of the household, including total amount of hours supplied, annual labor income, and industry. The latter is available at the three-digit level. For hours we use the variable "Head Annual Hours of Work." This variable represents the total annual work hours for all jobs including overtime. For labor income, we use the variable "Head Wage," which includes wages and salaries. We deflate salaries using the CPI deflator.

\section{Summary of Available Information: QCEW vs. PSID vs. Glassdoor}

Table 2 compares the information available in Glassdoor to the corresponding information in QCEW and PSID. Glassdoor data offer many advantages relative to the other two datasets. In Glassdoor, labor income is available at the worker level. Glassdoor also offers information on the job title, employer, and industry. PSID offers information on the three-digit occupation/industry of the worker, which is broader than the exact job title. Moreover, both Glassdoor and QCEW include detailed geographical information while PSID does not. At the same time, data from Glassdoor have a few shortcomings. As mentioned earlier, Glassdoor is a repeated cross-section of workers and not a panel. Moreover, there is no information on working hours on Glassdoor, although there is some information on part-time versus full-time work.

\section{MEASUREMENT ISSUES}

We compare Glassdoor with a) QCEW in terms of employment shares and average wages by industry and geographic area and b) PSID in terms of average wages and dispersion in wages by industry. Industries in Glassdoor are not directly comparable to industries in QCEW and PSID. Glassdoor uses an industry descriptor that roughly corresponds to four-digit industry codes. Some examples of industries or 
Table 2 QCEW vs. PSID vs. Glassdoor

\begin{tabular}{l|ccc}
\hline & QCEW & PSID & Glassdoor \\
\hline Worker ID & X & $\checkmark$ & $\checkmark$ \\
Job Title & X & X & $\checkmark$ \\
Occupation & X & $\checkmark$ & X \\
Employer & X & X & $\checkmark$ \\
Industry & $\checkmark$ & $\checkmark$ & $\checkmark$ \\
Location & $\checkmark$ & X & $\checkmark$ \\
Panel Data & $\checkmark$ & $\checkmark$ & X \\
Information on Labor Income & $\checkmark$ & $\checkmark$ & $\checkmark$ \\
Information on Hours & X & $\checkmark$ & X \\
Survey & $\checkmark$ & $\checkmark$ & $\checkmark$ \\
\hline
\end{tabular}

Notes: Comparison between datasets: QCEW, PSID, and Glassdoor.

industry bundles are accounting and legal, consumer services, finance, government, health care, real estate, retail, information technology, manufacturing, and others. Glassdoor does offer a narrower definition of industries (such as car rentals, bars and restaurants, oil and gas exploration, airlines, and other groups of economic activity), but this information is not available for all entries, so we use the broader industry definition.

Our first task is, therefore, to match as closely as possible the industry sectors reported in Glassdoor and QCEW. For some industry categories, there is a direct mapping between the two databases. Some examples are manufacturing; arts, entertainment, and recreation; real estate; business services; telecommunications; and retail. For other sectors, we construct a mapping using a bundle of industries from QCEW. As an example, for biotech and pharmaceuticals, we use industry codes 3254 and 5417, which correspond to pharmaceutical and medicine manufacturing and scientific research and development, respectively. Matching geographical areas between Glassdoor and QCEW is a more straightforward exercise. In particular, to make geographic areas consistent across databases, we merge cities to the appropriate MSA.

Matching industries between Glassdoor and PSID also involves combining different industry codes in PSID and matching them to a corresponding sector in Glassdoor. For example, for accounting/legal we combine industry codes 727 and 728 in the PSID to get the closest possible match, while for government, we combine fifteen different industry codes, ranging from 937 to 987.

A second issue is to transform hourly rates to annual salaries because in Glassdoor, 34 percent of user entries report compensation in 
Karabarbounis \& Pinto: What Can We Learn from Online Wage Postings?181

Table 3 Employment Shares By Industry

\begin{tabular}{lrr}
\hline & & \\
Sector & QCEW & Glassdoor $(\%)$ \\
\hline Accounting/Legal & 1.00 & 2.99 \\
Aerospace/Defense & 0.39 & 2.21 \\
Agriculture/Forestry & 0.30 & 0.24 \\
Arts/Entertainment/Recreation & 1.80 & 1.41 \\
Biotech/Pharmaceuticals & 0.38 & 1.94 \\
Business services & 18.90 & 11.02 \\
Construction/Repair/Maintenance & 5.18 & 1.58 \\
Consumer Services & 3.98 & 1.11 \\
Education & 2.40 & 6.52 \\
Finance & 1.13 & 7.55 \\
Government & 4.96 & 2.72 \\
Health Care & 15.22 & 7.33 \\
Information Technology & 2.37 & 13.35 \\
Insurance & 1.69 & 2.60 \\
Manufacturing & 9.93 & 8.37 \\
Media & 0.11 & 2.48 \\
Mining/Metals & 0.13 & 0.11 \\
Oil/Gas/Energy/Utilities & 0.26 & 1.85 \\
Real Estate & 1.34 & 1.20 \\
Restaurants/Bars/Food services & 9.09 & 3.89 \\
Retail & 14.79 & 13.02 \\
Telecommunications & 0.66 & 2.71 \\
Transportation/Logistics & 3.28 & 2.04 \\
Travel/Tourism & 0.72 & 1.77 \\
\hline All sectors & 100.00 & 100.00 \\
\hline & &
\end{tabular}

Notes: Employment shares by industry in QCEW and Glassdoor.

hourly rates. We transform hourly rates into annual salaries by multiplying the hourly rate by 2,000 hours, which is about the average hours worked for a full-time worker per year. We then calculate average salary in industry/area $i$ as follows:

Average salary $_{i}=\left\{\begin{array}{c}\text { fraction salaried workers } i \\ + \\ + \text { average salary }_{i} \\ \text { fraction hourly paid workers } i\end{array}\right.$

\section{RESULTS}

In this section, we compare employment shares and average wages across industries and areas between Glassdoor and QCEW. We also compare average and standard deviation in wages across industries between Glassdoor and PSID. For Glassdoor, we use the cumulative data between 2010-17; for QCEW, we use the averages for the period 
Table 4 Employment Shares for Selected MSAs

\begin{tabular}{lrr}
\hline \hline MSA & QCEW $(\%)$ & Glassdoor $(\%)$ \\
\hline Atlanta & 2.30 & 3.36 \\
Boston & 2.42 & 3.82 \\
Chicago & 3.45 & 5.52 \\
Detroit & 1.76 & 1.57 \\
Houston & 2.21 & 2.88 \\
Los Angeles & 3.26 & 5.57 \\
Miami & 2.28 & 1.71 \\
New York & 7.24 & 8.92 \\
Philadelphia & 2.18 & 0.28 \\
Seattle & 1.92 & 3.51 \\
\hline 10 Large MSAs & 29.02 & 37.14 \\
\hline
\end{tabular}

Notes: Employment shares by selected geographical area (MSAs) in QCEW and Glassdoor.

2010-16; and for the PSID, we use averages for the period 2003-11. It is possible that some of the differences between Glassdoor and PSID arise due to the different time periods analyzed.

\section{Employment Shares: Glassdoor vs. QCEW}

We compare employment shares in a given industry or region in Glassdoor with the respective shares in QCEW. Employment share in Glassdoor is the share of entries in a given industry or region relative to the total number of respondents. Employment share in QCEW is the total number of employed workers in an industry or region as a fraction of total employment.

Table 3 shows employment shares by industry for all years. The observations from Glassdoor are significantly underrepresented in a number of industries including business services, construction, restaurants, food services, and, more importantly, health care. In contrast, Glassdoor is overrepresented in information technology and finance, among others. The correlation between the variables from the two databases is 0.65 .

Table 4 describes employment shares obtained from the two databases for ten large US MSAs. From the table, it is clear that large MSAs tend to be overrepresented in Glassdoor. Specifically, employment shares for the ten large MSAs reported in the table is about 37 percent in Glassdoor, and 29 percent in QCEW.

Figure 2 compares employment shares by MSA between QCEW and Glassdoor for all MSAs. We also include a linear fit. The correlation 
Karabarbounis \& Pinto: What Can We Learn from Online Wage Postings?183

\section{Figure 2 Employment Shares by MSA}

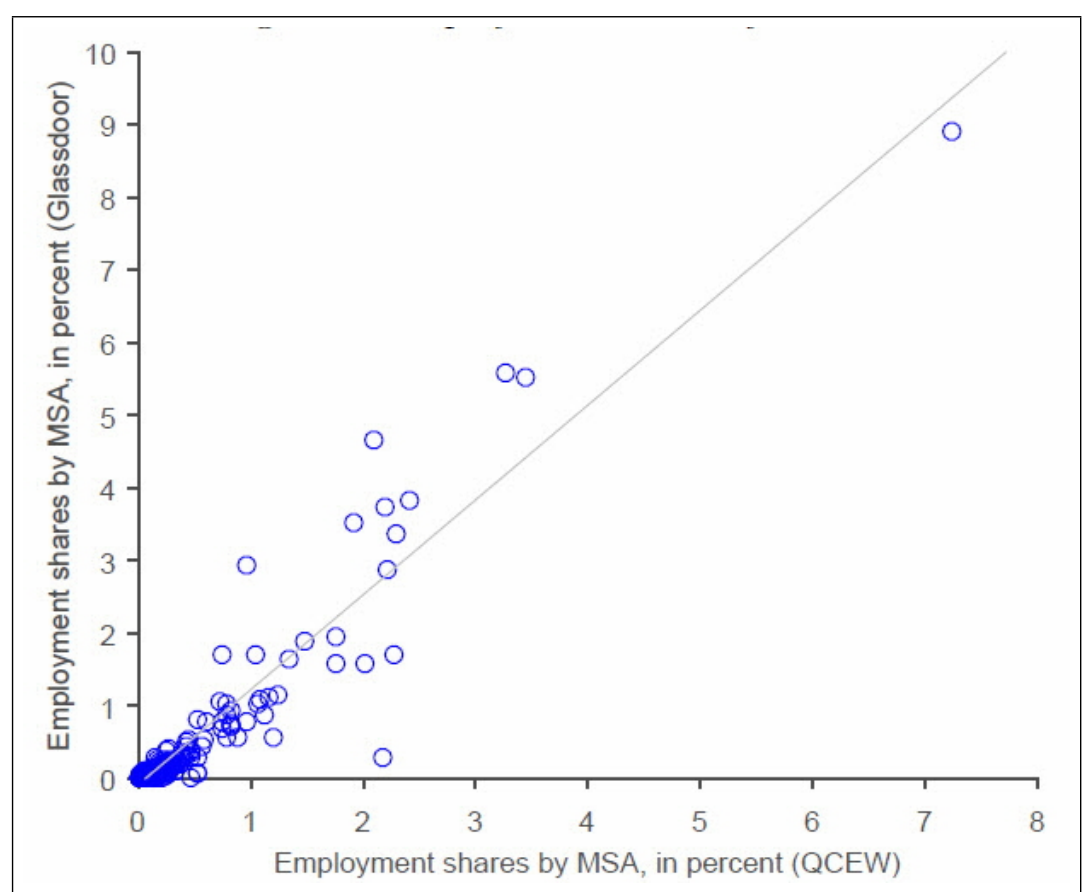

Notes: Employment shares for all geographical area (MSAs) in QCEW and Glassdoor.

is very high, equal to 0.94, which suggests that Glassdoor data are substantially more representative at the MSA level than at the industry level. MSAs with low employment shares (less than 2 percent) seem to be equally represented in both databases. The largest discrepancies are observed for MSAs with relatively large employment shares. As stated earlier, Glassdoor tends to attract respondents disproportionately from those large MSAs.

\section{Average Salaries: Glassdoor vs. QCEW}

In this section, we compare average salaries betwen Glassdoor and QCEW. We start by analyzing some salary statistics from Glassdoor. In Figure 3, we plot the distribution of reported salaries and hourly rates, respectively, as they appear in Glassdoor data for all years. The panel on the left shows the distribution of hourly rates. We have 


\section{Figure 3 Distribution of Hourly Rates and Salaries in Glassdoor}

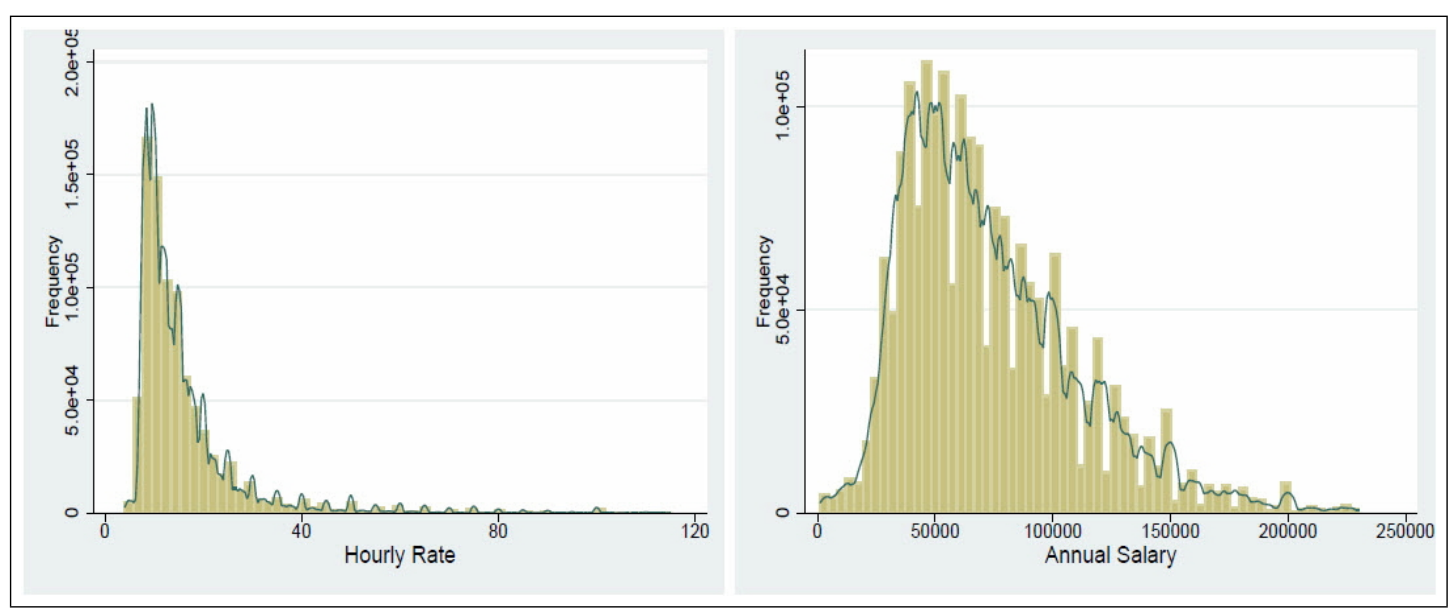

Notes: Left panel: Distribution of hourly rates in Glassdoor. Right panel: Distribution of annual salaries in Glassdoor.

dropped observations reporting less than $\$ 4$, which roughly corresponds to half the minimum wage, and also trimmed the top 1 percent of the distribution. The panel on the right shows the distribution of annual salaries. For salaried workers, we dropped observations with less than $\$ 1,000$ annually and again trimmed the top 1 percent of the distribution.

As mentioned, around 34 percent of user entries report jobs paid in hourly rates. The median hourly rate is $\$ 13$. The bottom 10 percent in the distribution receives $\$ 8.41$, while the top 10 percent receives $\$ 25$. Salaried workers account for approximately 64 percent of user entries in Glassdoor. ${ }^{4}$ The median annual salary is $\$ 65,000$. The bottom 10 percent in the distribution receives $\$ 35,000$, while the top 10 percent receives $\$ 125,000$.

So how do the average salaries reported in Glassdoor compare to those in QCEW? Table 5 shows average salaries by industry.

The average wages line up reasonably well for transportation $(\$ 48,106$ in QCEW vs. $\$ 46,966$ in Glassdoor), construction (\$54,826 vs. $\$ 57,534)$,

\footnotetext{
${ }^{4}$ As mentioned before, the rest of the workers, around 2 percent, report their labor earnings in a monthly frequency. For simplicity, we will abstract from this group in our analysis.
} 
Karabarbounis \& Pinto: What Can We Learn from Online Wage Postings?185

Table 5 Average Annual Salaries by Industry

\begin{tabular}{lcc}
\hline & & \\
Industry & QCEW $(\$)$ & Glassdoor $(\$)$ \\
\hline Accounting/Legal & 79,087 & 69,065 \\
Aerospace/Defense & 94,501 & 74,965 \\
Agriculture/Forestry & 27,458 & 53,896 \\
Arts/Entertainment/Recreation & 36,118 & 39,395 \\
Biotech/Pharmaceuticals & 116,956 & 76,298 \\
Business Services & 67,175 & 58,775 \\
Construction/Repair/Maintenance & 54,826 & 57,534 \\
Consumer Services & 32,905 & 40,171 \\
Education & 47,096 & 43,732 \\
Finance & 113,685 & 64,126 \\
Government & 52,966 & 61,991 \\
Health Care & 47,061 & 53,940 \\
Information Technology & 89,989 & 81,908 \\
Insurance & 76,132 & 59,937 \\
Manufacturing & 64,999 & 63,964 \\
Media & 88,090 & 62,987 \\
Mining/Metals & 86,408 & 66,943 \\
Oil/Gas/Energy/Utilities & 122,102 & 72,498 \\
Real Estate & 52,509 & 51,805 \\
Restaurants/Bars/Food Services & 17,309 & 28,341 \\
Retail & 28,770 & 36,906 \\
Telecommunications & 78,223 & 62,448 \\
Transportation/Logistics & 48,106 & 46,966 \\
Travel/Tourism & 32,776 & 42,081 \\
\hline & &
\end{tabular}

Notes: Average annual salaries in QCEW and Glassdoor by industry.

education ( $\$ 47,096$ vs. $\$ 43,732)$, arts and entertainment ( $\$ 36,118$ vs. $\$ 39,395)$, real estate $(\$ 52,509$ vs. $\$ 51,805)$, and manufacturing $(\$ 64,999$ vs. \$63,964). Overall, the correlation between QCEW and Glassdoor is 0.87 .

In Figure 4, we perform a similar comparison across MSAs. In particular, we compare the average salary in a location, as it appears in QCEW, with the average salary in the area from Glassdoor. The correlation between the two is 0.83 .

\section{Average Salaries: Glassdoor vs. PSID}

In this section, we compare data between Glassdoor and PSID. Both datasets are available at the worker level. We focus on the average salary and the dispersion of the wage distribution (standard deviation). As mentioned, we perform only crossindustry comparisons as detailed geographical information are not available in the PSID. The median industry in the PSID includes 659 observations. The largest number of 
Figure 4 Average Annual Salaries by MSA

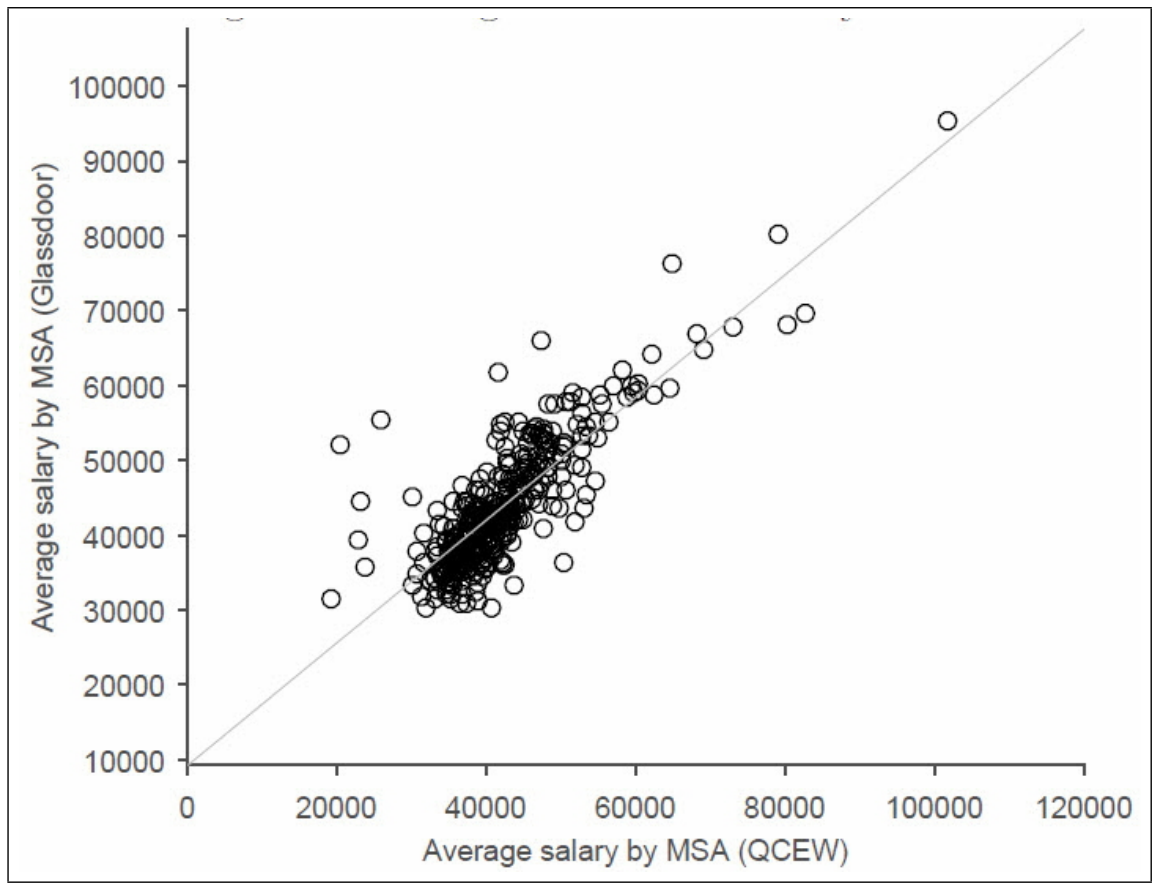

Notes: Average annual salaries in QCEW and Glassdoor by MSA.

observations is in manufacturing $(4,665)$, and the smallest is in mining (136). The left panel in Figure 5 plots average salary by industry in PSID and Glassdoor, respectively. The right panel in Figure 5 plots the standard deviation of annual salaries across industries in PSID and Glassdoor. Table 6 gives the numbers used to construct the right panel in Figure 5. The correlation in average salaries between PSID and Glassdoor is even higher than the one with QCEW, equal to 0.9. However, the within-industry dispersion in salaries in Glassdoor is not as close to the PSID as the correlation in average salary. The correlation is 0.77 . 
Karabarbounis \& Pinto: What Can We Learn from Online Wage Postings?187

Figure 5 Average and Standard Deviation of Annual Salaries by Industry

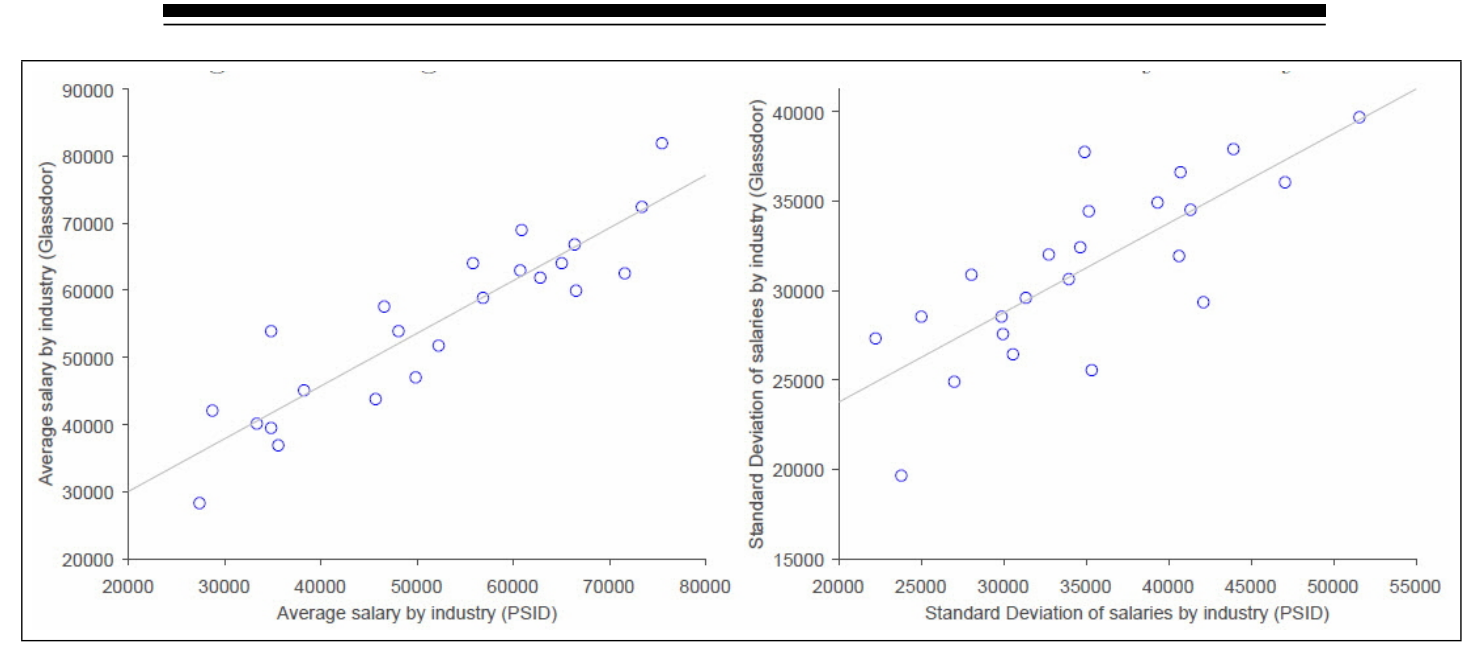

Notes: Left panel plots average annual salaries by industry for PSID and Glassdoor. Right panel plots standard deviation of annual salaries by industry in PSID and Glassdoor.

\section{CONCLUSION AND SUMMARY OF FINDINGS}

Glassdoor collects and records millions of observations on salaries by job titles, companies, and cities. The purpose of our paper is to evaluate the extent to which the salary data reported by Glassdoor replicates more traditional datasets, namely QCEW and the PSID. Our findings are summarized in Table 7 . The correlation between industry employment shares in Glassdoor and QCEW is relatively low, equal to 0.65. The correlation between MSA employment shares in Glassdoor and in QCEW is higher though, equal to 0.94. Regarding average annual wages, the correlation is fairly high, namely 0.87 across industries and 0.83 across MSAs. Finally, the correlation in average salaries between Glassdoor and PSID is 0.90, and in industry-wide dispersion in salaries it is 0.77 . 
Table 6 Standard Deviation in Annual Salaries

\begin{tabular}{lcc}
\hline Sector & Glassdoor $(\$)$ & PSID $(\$)$ \\
\hline Accounting/Legal & 36,018 & 47,053 \\
Agriculture/Forestry & 30,870 & 28,019 \\
Arts/Entertainment/Recreation & 28,528 & 29,815 \\
Business services & 34,478 & 41,293 \\
Construction/Repair/Maintenance & 29,624 & 31,317 \\
Consumer Services & 28,542 & 25,007 \\
Education & 24,872 & 26,994 \\
Finance & 37,913 & 43,916 \\
Government & 32,010 & 32,696 \\
Health Care & 30,659 & 33,966 \\
Information Technology & 39,702 & 51,549 \\
Insurance & 31,917 & 40,614 \\
Manufacturing & 34,425 & 35,171 \\
Media & 36,654 & 40,699 \\
Mining/Metals & 32,377 & 34,625 \\
Nonprofit & 25,517 & 35,291 \\
Oil/Gas/Energy/Utilities & 34,889 & 39,344 \\
Real Estate & 29,345 & 42,060 \\
Restaurants/Bars/Food services & 19,611 & 23,740 \\
Retail & 27,554 & 29,957 \\
Telecommunications & 37,715 & 34,937 \\
Transportation/Logistics & 26,401 & 30,528 \\
Travel/Tourism & 27,363 & 22,244 \\
\hline
\end{tabular}

Notes: Standard deviation in annual salaries in PSID and Glassdoor by industry.

Table 7 Summary of Findings

\begin{tabular}{lccl}
\hline Correlations & Industries & Areas & Data \\
\hline Employment share & 0.65 & 0.94 & Glassdoor/QCEW \\
Avg. annual salaries & 0.87 & 0.83 & Glassdoor/QCEW \\
Avg. annual salaries & 0.90 & N/A & Glassdoor/PSID \\
St. dev. annual salaries & 0.77 & N/A & Glassdoor/PSID \\
\hline
\end{tabular}


Karabarbounis \& Pinto: What Can We Learn from Online Wage Postings?189

\section{REFERENCES}

Chamberlain, Andrew, and Mario Nunez. 2016. "Glassdoor Local Pay Reports Methodology." Glassdoor Research Studies (December).

Hershbein, Brad, and Lisa B. Kahn. 2017. "Do Recessions Accelerate Routine-Biased Technological Change? Evidence from Vacancy Postings." Working Paper 22762. Cambridge, Mass.: National Bureau of Economic Research. (September).

Kudlyak, Marianna, Damba Lkhagvasuren, and Roman Sysuyev. 2013. "Systematic Job Search: New Evidence from Individual Job Application Data." Federal Reserve Bank of Richmond Working Paper 12-03R (September).

Solon, Gary, Steven Haider, and Jeffrey Wooldridge. 2013. "What Are We Weighting For?" Working Paper 18859. Cambridge, Mass.: National Bureau of Economic Research. (February). 